\title{
PRÁTICAS TURÍSTICAS E ORDENAMENTO TERRITORIAL NA ORLA MARÍTIMA DO MUNICÍPIO DE CORURIPE/AL ${ }^{1}$
}

\author{
Jucileide da Silva Sobreira ${ }^{2}$ \\ José Wellington Carvalho Vilar ${ }^{3}$
}

\section{Resumo}

O presente artigo tem por objetivo analisar as práticas turísticas e as iniciativas de ordenamento territorial desenvolvidas em duas praias do município de Coruripe, Pontal de Coruripe e Lagoa do Pau - Alagoas - Brasil. O turismo é uma prática sócio-espacial que vem crescendo muito nas últimas décadas, principalmente no segmento sol e praia, cuja ação viabiliza o uso e a apropriação da natureza no litoral desencadeando um conjunto variado de implicações socioambientais, econômicas, culturais e na configuração territorial. Em termos metodológicos, além da observação simples, utilizou-se registros fotográficos, entrevistas e caderno de campo com anotações sobre usos e práticas turísticas e ordenamento territorial. Constatou-se que o uso da orla marítima do Pontal de Coruripe e da Lagoa do Pau está associado ao lazer, ao veraneio e às atividades pesqueiras. Ademais, há ausência de fiscalização e de controle das práticas turísticas por parte dos órgãos competentes e de ações de gerenciamento costeiro.

Plavras-chave: Turismo; Ordenamento Territorial; Orla Marítima.

\section{TOURISM PRACTICES AND SPATIAL PLANNING IN THE OCEANFRONT OF THE CORURIPE MUNICIPALITY/ AL}

\begin{abstract}
The objective of this article is to analyze tourism practices and spatial planning initiatives developed on two beaches in the municipality of Coruripe, Pontal de Coruripe and Lagoa do Pau - Alagoas - Brazil. Tourism is a socio-spatial practice that has been growing a lot in the last decades, mainly in the sun and beach segment, whose action makes possible the use and the appropriation of nature on the coast, triggering a varied set of socio-environmental, economic, cultural and territorial implications. In methodological terms, in addition to the simple observation, photographic records, interviews and field notes with annotations on uses and tourist practices and territorial planning were used. It was found that the use of the

\footnotetext{
${ }^{1}$ Trabalho resultante da Pesquisa de Mestrado, ainda em fase conclusão, junto ao Programa de Pós-Graduação em Geografia da Universidade Federal de Sergipe (PPGEO/UFS), intitulada preliminarmente de Usos e Práticas Turísticas na Orla de Coruripe-AL.

${ }^{2}$ Mestranda do Programa de Pós-Graduação em Geografia da Universidade Federal de Sergipe (PPGEO/UFS). Membro do Grupo de Pesquisa em Gestão Territorial de Ambientes Costeiros do Instituto Federal de Sergipe (GESTAC/IFS) e do Grupo de Estudos e Pesquisas em Análise Regional da Universidade Federal de Alagoas (GEPAR/UFAL). E-mail: jucisobreira@gmail.com.

${ }^{3}$ Professor Titular do Instituto Federal de Sergipe (IFS) e colaborador do Programa de Pós-Graduação em Geografia da Universidade Federal de Sergipe (PPGEO/UFS). Líder do Grupo de Pesquisa Gestão Territorial de Ambientes Costeiros (GESTAC/IFS). E-mail: wvilar@yahoo.com.br
} 
seafront of Pontal de Coruripe and Lagoa do Pau is associated with leisure, second home and fishing activities. In addition, there is absence of inspection and control of the tourist practices by the competent bodies and actions of coastal management.

Key-words: Tourism; Spatial Planning; Oceanfront.

\section{TURISMO INTERNACIONAL: TENDENCIAS MODERNAS, MODELOS Y PROCESSOS}

\section{Resumen}

El presente artículo tiene por objetivo analizar las prácticas turísticas y las iniciativas de ordenación territorial desarrolladas en dos playas del municipio de Coruripe, Pontal de Coruripe y Lagoa do Pau - Alagoas - Brasil. El turismo es una práctica socio-espacial que ha crecido mucho en las últimas décadas, principalmente en el segmento sol y playa, cuya acción viabiliza el uso y la apropiación de la naturaleza en el litoral desencadenando un conjunto variado de implicaciones socioambientales, económicas, culturales y en la configuración territorial. En términos metodológicos, además de la observación simple, se utilizaron registros fotográficos, entrevistas y cuaderno de campo con anotaciones sobre usos y prácticas turísticas y ordenación territorial. Se constató que el uso de la orilla marítima del Pontal de Coruripe y de la Laguna del Pau está asociado al ocio, al veraneo y a las actividades pesqueras. Además, hay ausencia de fiscalización y de control de las prácticas turísticas por parte de los órganos competentes y de acciones de gestión costera.

Palabras-clave: Turismo; Ordenación Territorial; Borde Litoral.

\section{INTRUDUÇÃO}

O turismo é uma prática sócio-espacial, econômica e cultural que vem crescendo muito nas últimas décadas, principalmente no segmento sol e praia, cuja ação viabiliza o uso e a apropriação da natureza no litoral desencadeando um conjunto variado de implicações socioambientais, econômicas, culturais e na configuração territorial.

Em seus variados segmentos, o turismo no espaço litorâneo tem gerado uma série de problemas que merecem ser discutidos, seja em termos de uso do solo ou das práticas que a atividade desenvolve. De maneira geral, esses problemas são resultantes do uso inadequado dos recursos turísticos e da forma como se leva a cabo a atividade.

No presente artigo parte-se do pressuposto que o espaço litorâneo é frágil, por se tratar de uma zona de transição entre o oceano e o continente, e apresenta uma valorização social e econômica crescente (MORAES, ZAMBONI, 2004). Essa natureza ambígua do litoral se revela nas formas que assume a configuração territorial, nas atividades de uso do espaço e nas ações da iniciativa privada e do poder público. Nesse sentido, as políticas de ordenamento 
territorial (OT) jogam um papel chave na configuração litorânea como um todo e da orla marítima em particular.

Vale ressaltar inicialmente que a produção do espaço turístico tem um caráter dual em termos de impactos positivos e negativos. Nos aspectos positivos, Diniz e Vasconcelos (2012) destacam a entrada de recursos nos centros receptores que resulta no aumento da dinâmica comercial e geração de emprego e renda para as comunidades tradicionais. Quanto ao fomento do Estado, impacta nas condições de vida das comunidades por meio de construção de estruturas, serviços urbanos, a exemplo de abastecimento de água, luz, telefone, saneamento básico, entre outros.

Em contrapartida, o turismo pode causar degradação ambiental e problemas de natureza socioeconômica associados à massificação da atividade e ao uso inadequado dos recursos, afetando inclusive sua viabilidade enquanto atividade econômica. Igualmente, podem ser introduzidos novos hábitos e costumes para as comunidades receptoras ocasionando mudanças culturais (DINIZ; VASCONCELOS, 2012), às vezes bem acentuadas, e crise nas atividades tradicionais, que vão disputar o espaço com o turismo.

Nesse contexto, o presente artigo tem por objetivo analisar as práticas turísticas e as iniciativas de ordenamento territorial desenvolvidas em duas praias do município de Coruripe, Pontal do Coruripe e Lagoa do Pau. Em outros termos, busca-se compreender a situação atual do turismo nas localidades supracitadas e as dinâmicas espaciais turísticas coordenadas pelas ações do poder público. A escolha dos referidos povoados justifica-se pela oferta turística municipal se encontrar localizada nessas duas localidades, definidas como espaços receptores pelos documentos oficiais de ordenamento territorial turístico do litoral alagoano (ALAGOAS, 2011).

\section{USOS E PRÁTICAS TURÍSTICAS}

O uso envolve um recurso, já as práticas abrangem também as relações subjetivas com o espaço, e ambos estão em uma relação de interação e dependência. No turismo litorâneo, o uso se dá a partir da apropriação dos recursos disponíveis e dos elementos contidos no espaço criando territórios turísticos através da delimitação do espaço pelas relações de poder e pela dinâmica do cotidiano, configurando assim territorialidades variadas.

Para compreender os usos e as práticas turísticas no litoral busca-se inicialmente discorrer sobre a concepção de espaço abordada por Milton Santos (2006). Para Santos (2006, 
p. 63), em sua definição clássica, “o espaço é formado por um conjunto indissociável, solidário e também contraditório de sistemas de objetos e sistemas de ações, não considerados isoladamente, mas como o quadro único no qual a história se dá." A análise do espaço para o referido autor se dá por meio desses dois sistemas, nos quais os objetos se associam às ações, e as ações se misturam aos objetos numa relação dinâmica e dialética.

Os objetos podem ser produzidos ou modificados pela ação do homem, e caracterizam-se basicamente por sua materialidade e visibilidade paisagística. São produtos construídos por relações socioeconômicas, políticas e culturais, ou por forçantes naturais e são carregados de valores simbólicos e funcionais. No que tange ao ambiente natural, Santos (2006) ressalta que o uso da natureza pelo homem a transforma em objeto. No turismo, a natureza é transformada em recurso por meio do uso antrópico dos atrativos ou pela construção de produtos turísticos. Já as ações são caracterizadas como as práticas desenvolvidas pelo homem, são reflexos de suas necessidades objetivas e subjetivas.

Atualmente, o turismo é considerado uma prática socioespacial e cultural e ao mesmo tempo uma atividade econômica e produtiva, é forma e ação. Os produtos turísticos são pensados e construídos para atender as muitas necessidades das atividades de viagens e lazer, e são compostos por elementos tangíveis e intangíveis (DIAS; AGUIAR, 2002).

A oferta turística se constitui de elementos naturais e artificiais. Segundo Dias e Aguiar (2002, p. 69), “os elementos básicos da categoria naturais incluem os corpos de água, as belezas naturais, o clima, a configuração física, a fauna e a flora." Os referidos autores consideram três subdivisões principais dos atrativos artificiais: a primeira inclui os aspectos históricos, culturais e religiosos, que compreendem as festas típicas, lugares históricos, exposições culturais, feiras de artesanatos, entre outros; a segunda, a infraestrutura, que é composto basicamente pelos meios de alimentação, alojamento, agência de turismo, centros de informações, entre outros; e a terceira, a via de acesso, que pode ser aquática, como o uso de barcos e navios, terrestres, a exemplo de ônibus e automóveis, e aéreos, principalmente aviões e helicópteros.

A demanda é compreendida a partir das motivações que levam o turista a viajar (PEARCE, 2003). As motivações podem ser variadas, envolvem aspectos psicológicos, físicos, e características objetivas e subjetivas do lugar. Em geral, a procura dos turistas se pauta por lugares diferentes do seu habitual, e no desejo de evadir-se do seu espaço cotidiano. Viajar também se tornou uma estratégia social de privilégio e do próprio capital que inventa 
lugares turísticos para reprodução de sua força e domínio. Seja como for, a mobilidade turística é inerente ao homem moderno e reflete o atual momento do capitalismo, a globalização. Nesse contexto, na atualidade há uma tendência de valorização dos ambientes naturais, como é o caso de praias paradisíacas, que muitas vezes tem sido acompanhado por uma ocupação predatória e por mudanças territoriais intensas.

Segundo Madruga (1992) e Moraes (2007), um dos principais vetores de ocupação territorial do litoral brasileiro é o turismo, o que justifica a importância de políticas territoriais de uso e ocupação do espaço para manter a sustentabilidade ambiental, social e econômica. $\mathrm{O}$ espaço litorâneo apresenta um rica biodiversidade e vulnerabilidade natural elevada, por se constituir um ambiente de transição entre ecossistemas aquáticos e terrestres, um valor social de prestígio representado principalmente pela atratividade da praia, e, igualmente, encontra um desenvolvimento de diversas atividades econômicas e de lazer, que são acompanhadas de conflitos, degradação ambiental e intensificação das formas de uso e ocupação da orla marítima e de seus espaços adjacentes.

O segmento de sol e praia é uma das modalidades turísticas que mais se destaca atualmente, principalmente no Nordeste brasileiro. Este segmento está constituído por “atividades turísticas relacionadas à recreação, entretenimento ou descanso em praias, em função da presença conjunta de água, sol e calor” (BRASIL, 2010, p. 14).

Nesse contexto, as práticas turísticas exercem grande pressão sobre a natureza, visto ter sido transformada em atrativo e produto do turismo, tornando-se sua matéria prima básica, pelo menos para o segmento de sol e praia. Ademais, diante da possibilidade de gerar recursos econômicos em curto prazo, são construídos projetos turísticos com ausência e/ou insuficiência de planejamento, muitas vezes sem considerar os danos a médio e longo prazo, o que pode acarretar degradação ambiental a partir de mudanças rápidas e intensas no destino turístico (CORIOLANO, 2007).

\section{ORDENAMENTO TERRITORIAL TURÍSTICO NO LITORAL}

No Brasil, a Política Nacional de Ordenamento Territorial (PNOT) visa ampliar e organizar as ações do Estado, articulando políticas de ordenamento do território e políticas de desenvolvimento regional e urbano. Segundo Melo (2010), a política de ordenamento territorial contempla aspectos coerentes com a realidade social, visto que buscam diminuir as desigualdades sócio-espaciais; aumentar o nível de democratização e representatividade dos espaços políticos, a partir da descentralização do poder e da participação popular; fomentar o 
comprometimento público do resgate, fortalecimento e respeito às múltiplas identidades culturais territoriais; e realizar integrações multiescalar e multiterritorial dos diferentes lugares.

Assim, o ordenamento territorial se caracteriza como um instrumento democrático, por envolver a comunidade local nas tomadas de decisões sobre o território, buscando integrar os interesses econômicos, sociais e ecológicos, como forma de promover o desenvolvimento social e econômico regional e/ou local. Mas, para isso, carece de uma articulação nas escalas administrativas para implementação de instrumentos de planejamentos que ordenem as diferentes formas de usos do território e as atividades econômicas (SANTOS, 2017).

$\mathrm{O}$ ordenamento territorial se mostra como uma importante ferramenta para o desenvolvimento sustentável, que implica no equilíbrio econômico e social aliado à qualidade de vida. Como mostram Gómez Orea e Gómez Villarino (2012, p. 36), "el término sostenible identifica un tipo de desarrollo sensato, basado en el equilibro de las tres dimensiones que lo forman: económica, social y ambiental, y orientado a la calidad de vida ${ }^{4}$."

A gestão do turismo de sol e praia se desenvolve por meio de instrumentos e medidas normativas, institucionais e legais e envolvem a legislação e políticas nacionais da zona costeira, da orla marítima, dos recursos hídricos, patrimoniais e ambientais (BRASIL, 2010). Os estados federados e os municípios estabelecem suas diretrizes a partir das normas gerais postas pela união, e a integração dessas políticas visa ao ordenamento territorial do espaço litorâneo, abarcando interesses econômicos, sociais e ambientais.

Nessa perspectiva, a participação governamental torna-se chave, a partir de uma série de iniciativas, como por exemplo, o fomento de infraestrutura, construção e aplicação de diretrizes e políticas públicas que subsidiem a prática sócio-espacial do turismo, considerando seus aspectos funcionais e suas implicações socioambientais. As participações da iniciativa privada e da comunidade local também são de suma importância para o desenvolvimento do turismo de forma sustentável, pois as práticas e os usos territoriais precisam ser socialmente justas, economicamente viáveis e ecologicamente duradouras (BRASIL, 2013).

Nesse viés, é na década de 1990 que o turismo passa a ser visto como uma atividade econômica que impulsiona o processo de desenvolvimento regional e local no Brasil. Dantas e Alves (2016) mostram que o II PND (Plano Nacional de Desenvolvimento) foi o primeiro documento a apontar o turismo enquanto atividade potencializadora de desenvolvimento

\footnotetext{
${ }^{4} \mathrm{O}$ termo sustentável identifica um tipo de desenvolvimento sensato, baseado no equilíbrio das três dimensões que o formam: econômico, social e ambiental, e orientado para a qualidade de vida.
} 
regional, e assim, foi considerado um importante instrumento de combate às desigualdades regionais. Cruz (2005) ressalta ainda que o processo de planejamento culmina a partir de 2003, com a criação do Ministério do Turismo.

O modelo atual de gestão adotado pelo Ministério do Turismo é descentralizado, formado por canais de interlocução a partir de instâncias de governança representadas pelo poder público, setor privado, associações e sociedade civil organizada (BRASIL, 2013).

Em âmbito Federal, o governo desenvolve várias políticas para ampliar esse setor, como por exemplo, a Política Nacional de Turismo (1996-1999), o Programa Nacional de Municipalização do Turismo (PNMT) de 2002, e o Plano Nacional de Turismo (PNT), o primeiro, de 2003 a 2007, o segundo, de 2007 a 2010, e o terceiro, de 2013 a 2016. Ademais, deve-se destacar o Programa de Ação para o Desenvolvimento do Turismo no Nordeste (PRODETUR-NE I e II), iniciado nos anos noventa, e o lançamento do Programa de Regionalização do Turismo (PRT) em 2013.

Nesse contexto, a Região Nordeste ganha ênfase, os governos estaduais elaboram individualmente suas políticas e captam recursos junto aos órgãos de fomento (DANTAS; ALVES, 2016), com o objetivo de transformar a região em um forte polo turístico, privilegiando o litoral e as orlas marítimas. Em outros termos, valoriza-se o modelo turístico de sol e praia em suas variadas vertentes. Nesse contexto, foram criadas estratégias de fortalecimento dos instrumentos públicos de fomento, como o Fundo Geral do Turismo (FUNGETUR), as linhas específicas de crédito do Banco Nacional de Desenvolvimento Econômico e Social (BNDES), e a elaboração de contrato entre Governo Federal e o Banco Interamericano de Desenvolvimento (BID) com vistas ao financiamento do PRODETUR I e II (CRUZ, 2005).

Em Alagoas, o governo do estado, em consonância com as diretrizes nacionais, elaborou políticas para promover o turismo, privilegiando seus espaços costeiros (ALAGOAS, 2013). Destaca-se o Programa de Regionalização do Turismo que teve como propósito implementar o novo modelo de gestão, descentralizada e participativa. A partir do Programa de Regionalização, Alagoas foi dividido nas seguintes regiões turísticas: Agreste; Caminhos do São Francisco; Costa dos Corais; Lagoas e Mares do Sul; Metropolitana; e Quilombos (MTUR, 2017-2019). No litoral se encontram quatro dessas regiões: Metropolitana, Costa dos Corais, Caminhos do São Francisco e Lagoas e Mares do Sul. Nesta última, responsável por 19,7\% dos meios de hospedagem do estado, se encontra o município aqui estudado. Os municípios que receberem maior fluxos de visitantes e possui destinos 
turísticos consolidados em Alagoas são: Roteiro, com destaque para a praia do Gunga, Marechal Deodoro, com a praia do Francês, e Barra de São Miguel, evidenciada pela praia de Barra de São Miguel e rio Niquim (ALAGOAS, 2015).

No Brasil, o ordenamento territorial turístico no litoral tem no Plano Nacional de Gerenciamento Costeiro (PNGC) um elemento basilar. Instituído pela Lei 7.661, de 16 de maio de 1988, como parte integrante da Política Nacional para os Recursos do Mar (PNRM) e da Política Nacional do Meio Ambiente (PNMA), o PNGC visa a orientar a utilização nacional dos recursos da zona costeira com base nas políticas de ordenamento territorial, prevê o zoneamento de uso e atividades da zona costeira e dá prioridade à conservação e proteção ambiental. Entre os objetivos do PNGC está a promoção do ordenamento do uso dos recursos naturais e da ocupação dos espaços costeiros, a implantação de uma gestão descentralizada e participativa e o diagnóstico da qualidade ambiental.

Em termos de gestão costeira, o Artigo 14 da Lei $\mathrm{n}^{\circ}$ 13.240, de 30 de dezembro de 2015, autoriza a transferência de gestão das praias marítimas urbanas, estabelecendo uma gestão compartilhada entre a União, Estado e o município. Este último, assina o termo de adesão que será analisado pela Secretaria do Patrimônio da União (SPU), e, igualmente, são estabelecidos critérios de garantia da equidade socioambiental das praias, como o uso e ocupação de acordo com o suporte do meio físico, ou seja, estabelecendo critérios de ordenamento territorial e turístico desses espaços.

Outro instrumento de ordenamento territorial do litoral que tem implicação jurídica no turismo é o Projeto de Gestão Integrada da Orla Marítima (Projeto Orla). Regulamentado pelo Decreto $n^{\circ} 5.300$, de 2004, o Projeto Orla é executado pela ação conjunta entre o Ministério do Meio Ambiente (MMA) e o Ministério do Planejamento e busca uma integração entre as políticas ambientais e patrimoniais visando ao ordenamento do uso e ocupação da orla marítima (MMA, 2006). Assim, a gestão ambiental integra as políticas de turismo e as diretrizes de uso e ocupação da orla marítima.

O Decreto $\mathrm{n}^{\circ}$ 5.300, de 7 de dezembro de 2004 (BRASIL, 2004), define e estabelece os critérios de gestão da orla marítima, que se caracteriza como "a área de contato imediato terra/mar e de interface de processos terrestres e aquáticos, sendo, portanto, a borda marítima, estuarina ou lagunar da zona costeira". (MORAES; ZAMBONI, 2004, p. 06).

Em Alagoas, o Projeto Orla iniciou suas atividades em 2008, sendo regulamentado pelo Decreto $\mathrm{n}^{\mathrm{o}} 4.098$, de 14 de janeiro de 2009, que institui a Coordenação Estadual do 
Projeto Orla e a Comissão Técnica de Acompanhamento (ALAGOAS, 2009). A Coordenação Estadual está vinculada à Secretaria de Estado do Meio Ambiente e dos Recursos Hídricos (SEMARH) e à Gerência do Serviço de Patrimônio da União em Alagoas (GRPU). A Comissão Técnica do Estado de Alagoas (CTE/AL) está vinculada ao Instituto do Meio Ambiente (IMA), e está atualmente composta por representantes e respectivos suplentes de órgãos e entidades da Administração Pública e da sociedade civil organizada (ALAGOAS, 2014).

O primeiro município a aderir e concluir o Projeto de Gestão Integrada da Orla Marítima (Projeto Orla) em Alagoas foi Paripueira, em 2010. Barra de São Miguel, Marechal Deodoro e Roteiro aderiram ao Projeto iniciando algumas ações, mas sem a consolidação do instrumento. Segundo o Relatório das Atividades de Gestão Costeira 2010/2014, os seguintes municípios aderiram ao Orla, mas não foi realizada ação alguma até o momento: Piaçabuçu, Maragogi e Pilar. Desde 2015, o município de Coruripe tem demonstrado interesse em aderir ao Projeto Orla nas reuniões desenvolvidas pela Coordenação Estadual ${ }^{5}$.

\section{METODOLOGIA}

\section{Área de estudo}

O município de Coruripe está localizado na região Sul do Estado de Alagoas e ocupa uma área de 917,66 km² (IBGE, 2010). Ademais, está inserido na Mesorregião do Leste Alagoano e na Microrregião de São Miguel dos Campos. Limita-se ao Norte com os municípios de Jequiá da Praia e Teotônio Vilela, ao Sul com Feliz Deserto e o Oceano Atlântico, a Oeste com Penedo e ao Leste com o Oceano Atlântico (Figura 1), e está distante cerca de 90 quilômetros da capital alagoana, Maceió, com acesso pela AL-101 sul.

Figura 1: Mapa de localização do município de Coruripe - AL

${ }^{5}$ Fonte: http://www.semarh.al.gov.br Acesso: 06/05/2018. 


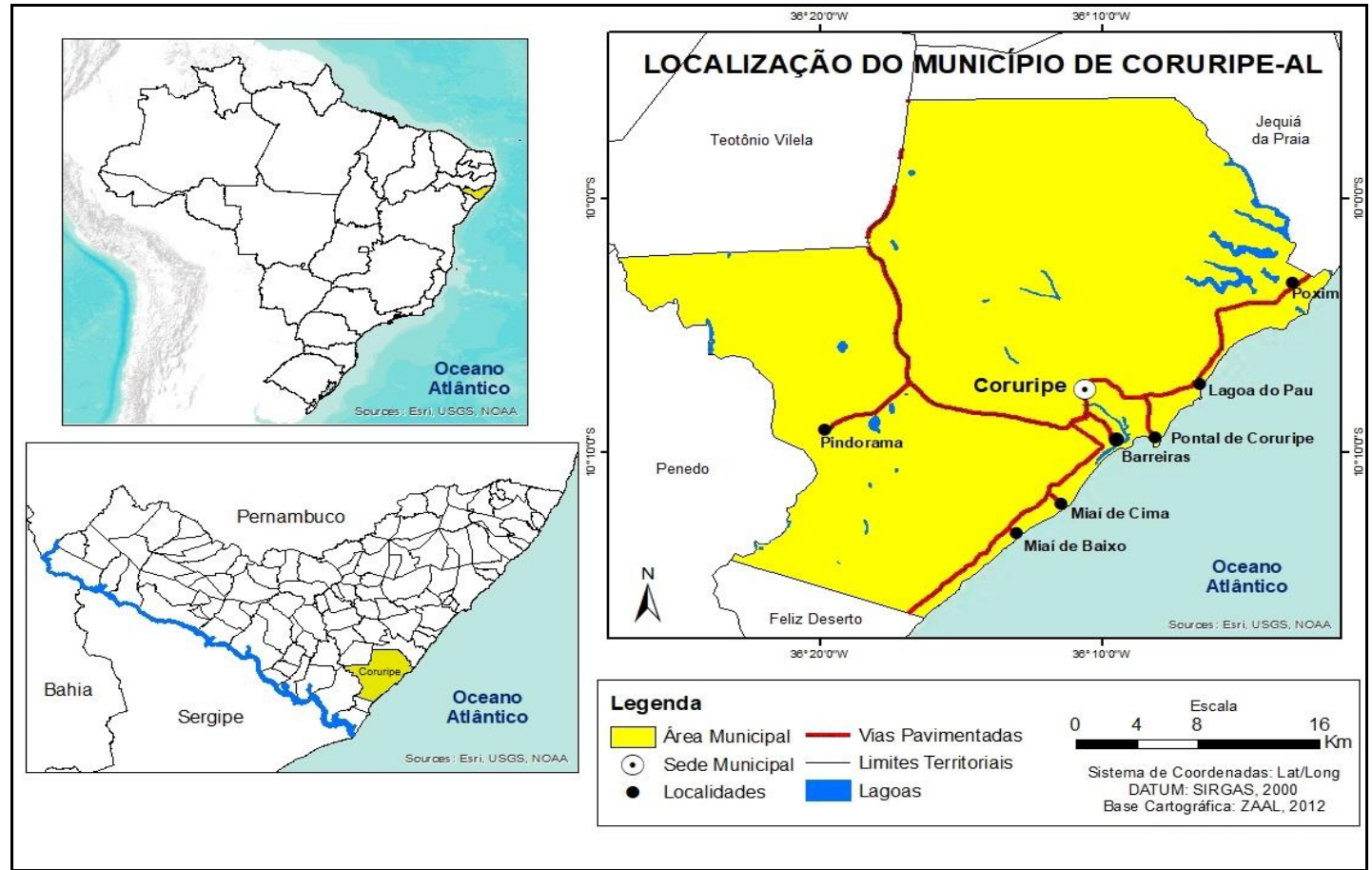

Fonte: Base Cartográfica ZAAL, 2012.

O processo de ocupação de Coruripe está alicerçado na monocultura da cana-deaçúcar, na construção dos engenhos e na exploração do trabalho escravo, assim como na história territorial do estado de Alagoas (DIÉGUES JÚNIOR, 2006). Coruripe era um pequeno povoado subordinado ao Poxim e os núcleos urbanos se desenvolveram nas proximidades da igreja Nossa Senhora da Conceição. Ao se destacar na economia, Coruripe assumiu um alcance mais regional, e em 1866 tornou-se vila, e em 1892 foi instituído enquanto cidade (PAIVA, 2010).

Os dados do último Censo Demográfico mostram que em 2010 a população passou a ser predominantemente urbana, com crescimento de 38,32\% em relação ao censo de 2000. Nesse período houve aumento no IDH, que passou para 0,628. Estima-se que em 2018 a população municipal seja de 56.562 habitantes. Em 2010, apresentou uma densidade demográfica de 56,77 hab/km² (IBGE, 2010).

$\mathrm{Na}$ agricultura do município de Coruripe destaca-se o cultivo da cana-de-açúcar e o coco-da-baía. Já na pecuária, verifica-se o predomínio de bovinos. Destaca-se também a produção de mel de abelha, leite e alevinos com a produção de tilápia e tambaqui (IBGE, 2016). A indústria é marcada pelo setor sucroalcooleiro e os serviços, pelo turismo. Em termos turísticos, Coruripe não se destaca entre os municípios mais visitados no litoral 
alagoano. É caracterizado enquanto turismo emergente, onde apenas as duas praias estudadas são consideradas turísticas (ALAGOAS, 2011).

A Costa coruripense tem uma extensão de aproximadamente $42 \mathrm{~km}$ e contempla os povoados Miaí de Baixo, Miaí de Cima, Barreiras, Pontal de Coruripe, Lagoa do Pau e Poxim. Entre os seus rios destacam-se o Coruripe, que deságua no povoado Barreiras, o rio Adriana, que forma o estuário no povoado Lagoa do Pau, e o rio Poxim, cuja foz se encontra no povoado homônimo. Dentre as lagoas destaca-se as seguintes: Escura, Guaxuma e Vermelha, ambas localizadas no povoado Poxim.

O povoado Pontal de Coruripe fica a $6 \mathrm{~km}$ da sede municipal e, segundo dados da Secretaria Municipal de Saúde (2018), possui cerca de 3.240 habitantes. Pontal se caracterizou como uma comunidade pesqueira, mas nas últimas décadas estão sendo introduzidas outras atividades, a exemplo do turismo e da tradicional vilegiatura marítima, mais conhecida como segunda residência. O povoado Lagoa do Pau está situado a $10 \mathrm{~km}$ da sede municipal e, segundo dados da Secretaria Municipal de Saúde (2018), apresenta cerca de 675 habitantes. As características pesqueiras do passado ainda prevalecem nos dias atuais, mais vale registrar o compartilhamento do uso da orla marítima com outras atividades, sobretudo com o turismo de segunda residência.

\section{Procedimentos metodológicos}

Para a realização deste artigo utilizou-se preferencialmente dados qualitativos. A presente pesquisa se caracteriza enquanto explicativa e caracteriza-se enquanto estudo de caso. Enquanto procedimento de coleta de dados utilizou-se observação simples para identificar os sujeitos que produzem o território turístico, e os usos e as práticas turísticas na orla marítima. Além da observação simples, utilizou-se de registro fotográfico e caderno de campo com anotações sobre os usos e práticas turísticas e as implicações do ordenamento territorial nessa atividade.

Também foram realizadas entrevistas com onze sujeitos da comunidade local e dois representantes do Poder Público Municipal. A amostragem foi composta por variados tipos de sujeitos. Segundo Turato (2003, p. 366), os sujeitos da amostragem devem ser "incluídos e reunidos pelo critério da homogeneidade fundamental; amostra fechada no número de tipos de informantes, segundo características várias eleitas deliberadamente pelo pesquisador." E quanto ao critério de homogeneidade, foram selecionados sujeitos adultos naturais ou moradores dos povoados de Pontal de Coruripe e Lagoa do Pau. Os tipos de informantes 
abrangem as diferentes atividades econômicas desenvolvidas localmente, a saber: pesca, artesanato, retirada de coco, venda ambulante, meios de alimentação e de hospedagens e atividades públicas. A amostra está distribuída da seguinte forma: a) No Pontal: um pescador, uma artesã, um tirador de coco, um vendedor ambulante, um proprietário de pousada e uma funcionária pública; b) Na Lagoa do Pau: um pescador, uma artesã, uma funcionária pública, um vendedor ambulante e um proprietário dos meios de alimentação; e c) dois representantes do setor público local, um da Secretaria Municipal de Turismo e outro da Secretaria Municipal de Meio Ambiente.

As entrevistas com os sujeitos sociais buscaram identificar: antecedentes históricos, os atrativos do lugar e as possíveis mudanças no espaço ocorrida a partir do uso e das práticas desenvolvida nas orlas. Já as entrevistas com os agentes públicos tiveram como objetivo compreender as políticas municipais de gestão do turismo de sol e praia. Buscou-se informações na Secretaria Municipal de Turismo sobre os segmentos turísticos desenvolvidos na atual gestão; locais que recebem maior fluxo de turistas e investimentos turísticos; impactos das políticas recentes voltadas para o fortalecimento desta atividade no município; e ações que a prefeitura vem realizando para fortalecer o turismo local.

Já para a entrevista com o representante da Secretaria do Meio Ambiente, buscou-se identificar os instrumentos de gerenciamento costeiro que o município aplica na gestão da orla marítima; como funciona a gestão, a limpeza e a fiscalização ambiental nas praias; quais as ações desenvolvidas pela prefeitura para prevenir ou sanar impactos ambientais decorrentes de descarte inadequado de lixo e de construções na orla de Coruripe.

\section{PONTAL DE CORURIPE E LAGOA DO PAU: USOS E PRÁTICAS TURÍSTICAS}

A análise dos usos e práticas turísticas se dará a partir do seguinte fio condutor: antecedentes históricos, atrativos e mudanças no espaço a partir da atividade turística. Os antecedentes históricos do turismo local indicam que a abertura do Pontal para o mar se deu a partir das relações comerciais estabelecidas pelo porto, que fora fundamental desde o período colonial. A população tem origem indígena e, posteriormente, os negros, em sua maioria escravizados, e os brancos europeus se somam à comunidade (LEMOS, 1999). A paisagem litorânea e marítima original era formada por grandes extensões de areia, coqueiros, mangues e pequenas casas de taipa cobertas com a palha de ouricuri ${ }^{6}$. As principais atividades

\footnotetext{
${ }^{6}$ Palmeira nativa da região. 
econômicas desenvolvidas estavam associadas à plantação de coqueiros, extração de sal e à pesca (PAIVA, 2010; SILVA, 2016).

Já o povoado Lagoa do Pau tem sua origem vinculada à pequenos lavradores que trabalhavam com a pesca como uma das principais atividades econômicas de subsistência, juntamente com a coleta de coco. Oriundos, principalmente, de outros povoados do próprio município, esses autóctones se aglomeraram por trás do cordão litorâneo e construíram suas residências nas proximidades da capela, antiga área de deposição sedimentar e atual praça do povoado.

Segundo dados coletados nas entrevistas, na Lagoa do Pau, na década de 1950, existiam em torno de cinco casas, a maior parte construída com palhas de ouricuri. Nesse período, os moradores da Lagoa do Pau eram originários da família Santana, fundadores do povoado. A principal base econômica estava alicerçada na agricultura, com o cultivo da batata, arroz, feijão e mandioca, juntamente com a pesca de tartaruga e o cultivo e a coleta de coco.

Os pescadores, naturais do povoado Lagoa do Pau, relatam que ao longo do tempo histórico não podiam mais utilizar as terras para o cultivo agrícola, em função da expansão das terras das usinas de açúcar do município, e por isso a pesca se tornou seu principal meio de subsistência. Vale ressaltar que essa questão da terra incentivou a migração dos trabalhadores rurais para áreas urbanas. Posteriormente, a consolidação da indústria canavieira no município se constituiu um marco importante para a permanência de alguns trabalhadores rurais, para urbanização do povoado e para a demanda turística em escala local.

Compreende-se que as características peculiares dos lugares se constituem em um dos principais atrativos turísticos: pequenas comunidades tradicionalmente pesqueiras que, antes da construção da AL-101 Sul, permaneciam mais isoladas proporcionando aos turistas desbravadores certa exclusividade. Há registros dos primeiros turistas, inclusive estrangeiros, em busca desse "paraíso tropical" representado por praias relativamente isoladas, de difícil acesso e com cenário paisagístico deslumbrante, nesse caso, o azul piscina do mar e a presença de falésias, arrecifes, lagoas e praias de areia fina que compõem o cenário natural que até hoje é objeto de interesse turístico e de visitação.

Verifica-se na costa do Pontal a presença constante de pequenas embarcações atracados na enseada, o que indica a presença de atividades de pesca na localidade. Essa característica já era predominante desde a década de 1960, como constata Silva (2016): mais de 100 jangadas em um período que somente existiam 200 casas. Já na Lagoa do Pau a 
presença de jangadas não é muito expressiva, os pescadores vão para alto-mar e passam dias pescando e ao retornarem, as jangadas e barcos pesqueiros são ancorados na zona de pós-praia ou na areia.

A oferta turística do litoral de Coruripe, o segundo componente para entender os usos e as práticas da orla do Pontal e da Lagoa do Pau, se constitui de elementos naturais que compõem a paisagem litorânea e elementos artificiais, aí inseridas as manifestações culturais. O patrimônio natural do município abrange as praias, as enseadas, a orla marítima, corpos hídricos, os remanescentes da Mata Atlântica, o ecossistema de manguezal, as várzeas, as matas ciliares e o mar. No que se refere aos elementos artificiais é possível categorizá-los em três grupos: o primeiro abrange os aspectos históricos, culturais e religiosos; o segundo, infraestrutura; e o terceiro corresponde às vias de acesso.

O principal atrativo natural do Pontal de Coruripe é a paisagem litorânea dominada pela praia, composta por recifes de arenito e enseadas, que diminuem a força das ondas e tornam as águas calmas, formando piscinas naturais, e pelos Baixios de Dom Rodrigo, que são recifes de arenito localizados próximo ao rio Coruripe, caracterizados enquanto elementos naturais e por seu valor histórico. $\mathrm{O}$ farol também é um elemento fundamental na composição da paisagem litorânea de Coruripe, inaugurado em 1948, e que compõe um conjunto de seis faróis administrados pela Capitania dos Portos de Alagoas.

No uso da orla marítima coruripense como um todo e especificamente nos dois povoados estudados desenvolvem-se práticas turísticas recreativas e de veraneio e atividades pesqueiras. As práticas recreativas se desenvolvem a partir da interação entre vários sujeitos que usufruem da orla marítima para o lazer e entretenimento. Práticas de passeios de jangada para apreciação da paisagem marítima e litorânea e mergulhos nas piscinas naturais também foram registradas no trabalho de campo.

$\mathrm{Na}$ pesquisa de campo foi identificado que o atrativo natural do turismo é a extensão da orla, com águas propícias para o surf, partes protegidas pelas extensões dos recifes de arenito, deixando as águas mais calmas, e o estuário do rio do Adriana. Essa configuração territorial tem atraído turistas, veranistas e surfistas. As práticas desenvolvidas são basicamente o banho de mar, o surf e os passeios de jangadas para contemplar os recifes de arenito que formam as piscinas naturais, essa última prática ocorre de forma aleatória, desenvolvida pelos moradores locais sem as devidas precauções. Seja como for, ainda não há produtos turísticos consolidados em Coruripe. 
Enquanto atrativo artificial, as características da pesca e a cultura do artesanato da palha de ouricuri (Figura 2) constituem elementos de identidade local dos povoados de Coruripe. A pesca está presente em todos os povoados à beira mar no município, já o artesanato encontra-se com maior expressividade no Pontal. Essas características mais rústicas e tradicionais também atraem turistas, visitantes e veranistas.

\section{Figura 2: Barcos atracados na orla e casa de artesanato do Pontal de Coruripe}

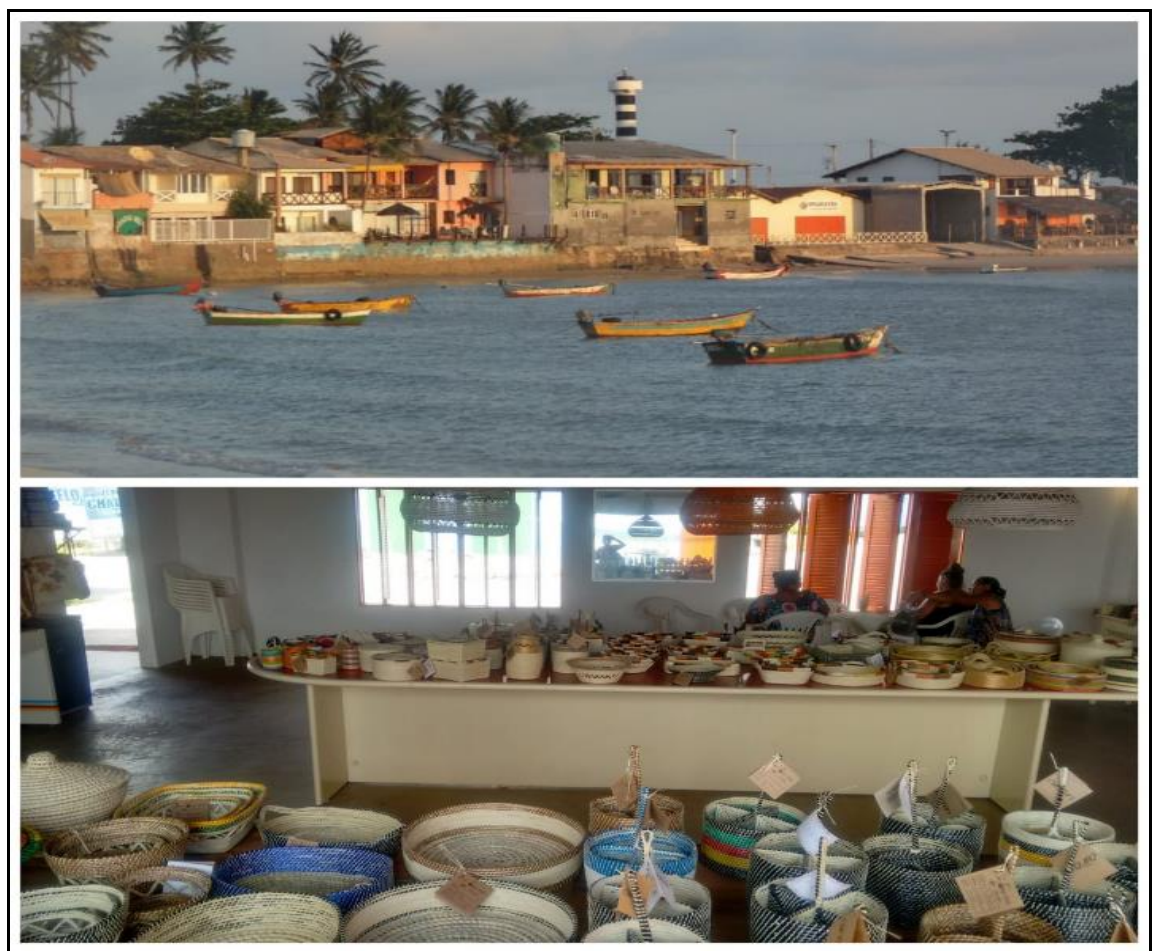

Fonte: Autores

No tocante à pesca, segundo o presidente da Colônia de Pescadores Z-10 ${ }^{7}$, localizada no Pontal de Coruripe, os principais tipos praticados atualmente são a de camarão, a pesca de arrasto, conhecida popularmente no local como lambuda, e a pesca de linha. As práticas pesqueiras são realizadas com embarcações denominadas de jangadas e com barcos pesqueiros. Aqui objetos e ações se comunicam e contribuem para a territorialidade local e para o fortalecimento da gastronomia, baseada, principalmente, em frutos do mar.

Já o artesanato, é geralmente confeccionado por mulheres como fonte de renda das famílias do Pontal desde a década de 1960 (SILVA, 2016). No Pontal de Coruripe, existem duas associações, a "Pontal Arte" e a "Associação das Artesãs do Pontal de Coruripe". Na Lagoa do Pau, foram registradas ações de uma associação em atividade há mais de 28 anos.

${ }^{7}$ Entrevista realizada em maio de 2018. 
No entanto, a comercialização do artesanato ocorre com maior frequência no Pontal, visto que os pontos de comercialização se encontram localizados nessa orla e há parcerias com a Usina Coruripe, SEBRAE, prefeitura e o Banco do Brasil. Na Lagoa do Pau, a associação localizase no núcleo de origem do povoado, afastado da orla e possui parceria apenas com a prefeitura $^{8}$.

O terceiro elemento selecionado em termos de uso e práticas turísticas corresponde às mudanças no espaço. O principal produtor de espaço da orla marítima de Coruripe é a vilegiatura marítima, compreendida neste trabalho como um fenômeno atual do turismo. Essa premissa é reforçada por Abrahão e Tomazzoni (2018), ao destacar que os impactos provocados pelos proprietários de segunda residência são similares aos desencadeados pelas diversas modalidades de turismo, como também, compartilha das mesmas necessidades.

O principal indutor da vilegiatura marítima em Coruripe foi o setor sucroalcooleiro, que tem fator significativo na construção territorial do município. No Pontal de Coruripe, Silva (2016) identifica que inicialmente são os usineiros, fazendeiros e trabalhadores especializados com altos salários que passaram a usufruir, como inquilinos temporários ou proprietários, das casas de veraneio na orla marítima, estabelecendo residências secundárias. Vale registar que ainda hoje é na rua Arapiraca onde se encontram residências secundárias dos usineiros no Pontal. Já na Lagoa do Pau, onde o fenômeno é mais recente, os primeiros veranistas são detentores de cargos de prestígio social, empresários, médicos, engenheiros de Arapiraca e do próprio município. Arapiraca parecer ter um forte vínculo territorial por meio da segunda residência com as orlas de Coruripe.

As mudanças territoriais verificadas a partir das práticas turísticas desenvolvidas nas orlas estão também associadas à construção de melhores acessos às praias, à abertura de condomínios residenciais e, principalmente, aos impactos causados pelos resíduos sólidos. Problemas de infraestrutura, vinculados à sazonalidade que tanto caracteriza áreas de vilegiatura marítima, também são verificados em Coruripe.

\section{ORDENAMENTO TERRITORIAL DAS ORLAS MARÍTIMAS DO PONTAL DE CORURIPE E DA LAGOA DO PAU}

Levando-se em conta que o segmento turístico de sol e praia local carece de políticas públicas nas várias esferas de governo, e, igualmente, se ressente de políticas ambientais,

\footnotetext{
${ }^{8}$ Entrevista realizada em setembro e novembro de 2018.
} 
patrimoniais e de uso e ocupação da orla marítima, buscou-se identificar quais os instrumentos de gestão do turismo do município de Coruripe. Identificou-se que o município possui um Plano Diretor, considerado o principal instrumento da política de ordenamento territorial urbano no Brasil, instituído pela Lei 1.276, de 03 de fevereiro de 2014 que tem como objetivo orientar a atuação do poder público municipal e a iniciativa privada. Vale ressaltar as premissas básicas dessa política: inclusão social, proteção ambiental, integração territorial e gestão compartilhada, todos com forte apelo turístico.

Para efetivação de uma administração descentralizada, o Estado de Alagoas formou grupos de gestão em escala estadual, regional e municipal, representados respectivamente pela Secretaria de Estado do Desenvolvimento Econômico e Turismo (SEDETUR), pelo Fórum Estadual de Turismo, pelas Instâncias de Governanças Regionais e pelos Grupos de Gestores Municipais (GOMES, 2015). Por sua vez, o município deve instituir o órgão oficial de Turismo, o Conselho/Fórum Municipal e o Interlocutor Municipal (BRASIL, 2013). Em Coruripe, o único órgão municipal de turismo é formado pela Secretaria Municipal de Turismo, o que já evidencia as dificuldades do setor para levar a cabo as estratégias e diretrizes que primem pela qualidade ambiental e pela descentralização.

Outro instrumento identificado na gestão territorial de Coruripe corresponde ao Plano Estratégico de Desenvolvimento do Turismo, no entanto, o representante da Secretaria de Turismo entrevistado reconhece que não se põe em prática, visto que a prefeitura não prioriza esse setor.

Os segmentos desenvolvidos na atual gestão são: sol e praia e o turismo ecológico. Segundo o representante da Secretaria de Turismo, o turismo cultural tem dificuldades de ser implementado no município, considerando as deficiências de transporte. Fator que acaba "isolando" os turistas que se limitam às praias de Coruripe, e esse fluxo se restringe praticamente às praias do Pontal e da Lagoa do Pau, embora Miaí de Baixo e Miaí de Cima apresentem evidências de segunda residência.

Quanto aos investimentos públicos e aos impactos das políticas recentes voltadas para fortalecer o turismo, o representante da Secretaria de Turismo não soube informar. Contudo, observa-se que os investimentos recentes no Pontal se resumem praticamente à construção da praça da orla, à reforma do farol e à edificação do Terminal Turístico (Figura 3).

Figura 3: Farol e Terminal Turístico do Pontal do Coruripe 


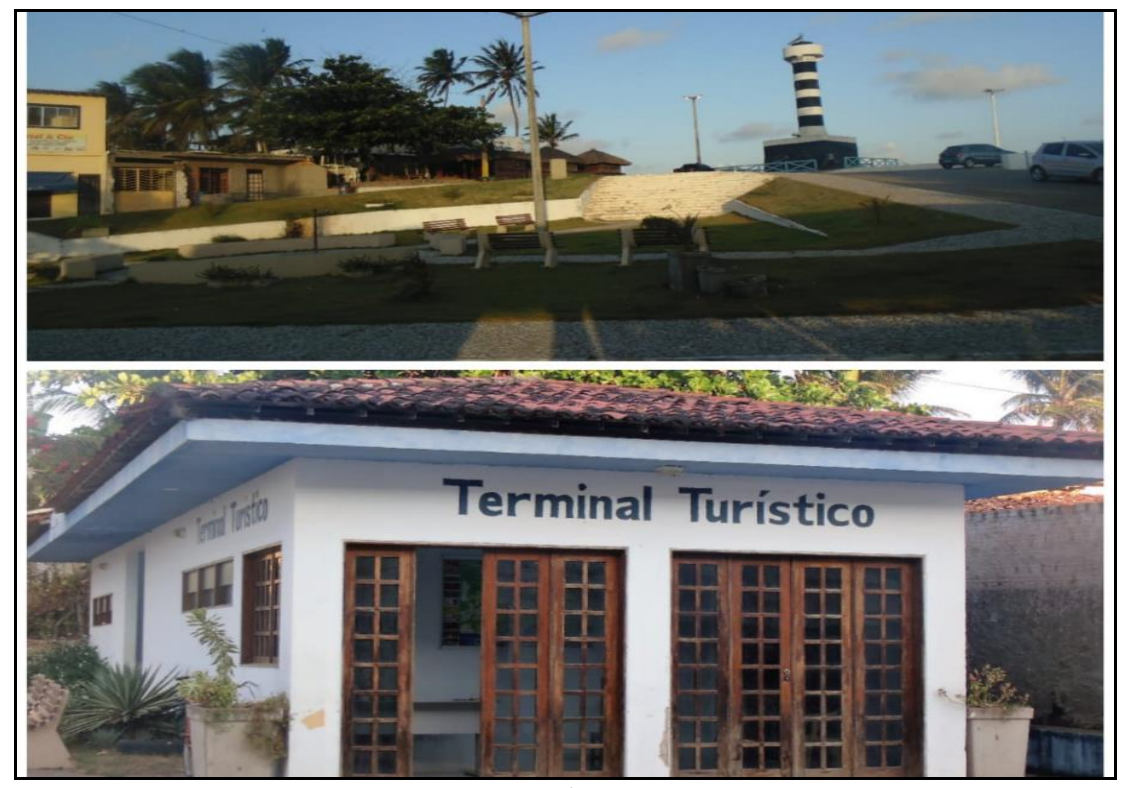

Fonte: Autores

Na Lagoa do Pau, observa-se investimento público na sinalização da praia para transportes (Figura 4), que produz territorialidades e tenta controlar os espaços da orla marítima, sobretudo em termos de estacionamento, na pavimentação das vias que dão acesso à praia, e na construção de uma via que interligará os dois principais destinos receptores de Coruripe, facilitando a fluidez territorial desses dois espaços.

Contudo, a Secretaria do Turismo não vem executando ações continuadas que promovam o desenvolvimento do turismo no município. Reconhece que o turismo só vai se desenvolver se houver parceria com os outros municípios do Polo Lagoa e Mares do Sul na construção de um roteiro integrado, pois é enfatizado que os Planos e Ações da Secretaria de Turismo do Estado e do Polo Lagoa e Mares do Sul até o momento pouco ou nada impactam no desenvolvimento do turismo em Coruripe.

Figura 4: Placas de sinalização de transporte na Lagoa do Pau 


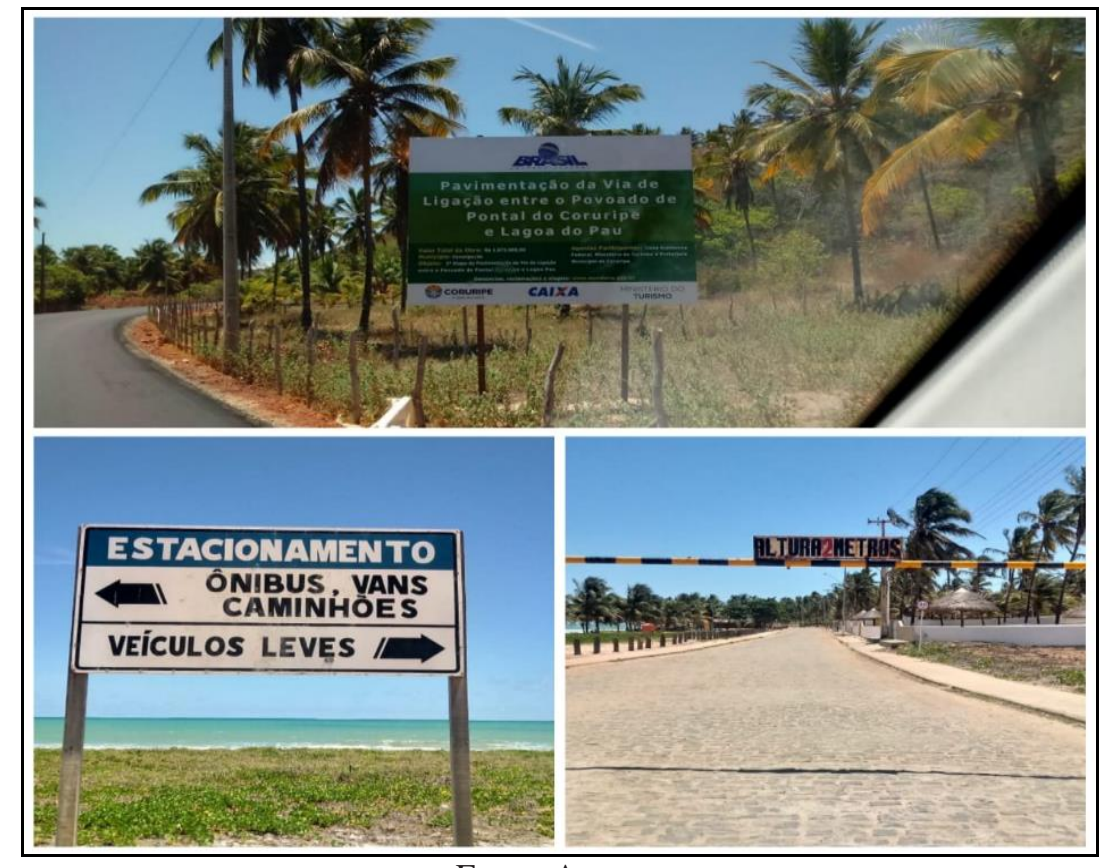

Fonte: Autores

Em termos de gestão da orla marítima, a Secretaria de Meio Ambiente tem papel fundamental no desenvolvimento do turismo e na fiscalização de construções em áreas de vulnerabilidade ambiental. No entanto, a fiscalização e gestão da orla marítima compete a SPU, embora o Decreto 13.240 de 2015 abra a possibilidade de estabelecer gestão compartilhada. Coruripe assinou o termo de adesão em agosto de 2018 de uma área que corresponde aos limites territoriais com o município de Jequiá da Praia até o povoado Lagoa do Pau.

O termo de adesão da orla marítima foi uma medida paliativa na contenção do conflito entre o Instituto do Meio Ambiente (IMA) e as barracas à beira mar na Lagoa do Pau que se encontram em processo de embargo, visto que foram construídas em áreas da União. Segundo informações dos entrevistados, a primeira cabana à beira-mar começou a funcionar no entorno das barracas dos pescadores, mas foi removida pela prefeitura há mais de vinte anos. Com o desenvolvimento das práticas recreativas nas orlas, a prefeitura removeu os barracos na tentativa de ordenar o espaço. Após a remoção das barracas, no início da década de 1990, iniciam-se construções de várias cabanas à beira mar. A primeira que já funcionava, fixou-se no local.

O representante da Secretaria Municipal do Meio Ambiente relatou que, embora a gestão e fiscalização seja competência da SPU, a prefeitura vem realizando fiscalizações das praias por meio dos salva-vidas, que ao identificar irregularidades comunicam a secretaria. No 
entanto, não compete aos mesmos essa função. A prefeitura não possui os instrumentos de gestão estabelecidos no Plano Nacional de Gerenciamento Costeiro que, na escala municipal, encontra-se em processo de construção.

Segundo os representantes do poder público entrevistados, a limpeza das praias é realizada diariamente, informação também relatada pelos moradores. No entanto, nota-se que a produção de lixo nos povoados é superior a demanda de limpeza, gerando uma situação que não combina com o cenário paisagístico, causa problemas de degradação ambiental e dificulta o take off do turismo.

Quando questionado sobre as ações desenvolvidas na prevenção e/ou resolução dos impactos ambientais, o representante da Secretaria de Meio Ambiente informou que vem sendo desenvolvidos projetos de sensibilização ambiental em parceria com o Instituto Amigo da Natureza (INAN). Um dos projetos mencionados se chama "Limpeza: Estamos Nessa", desenvolvido todo mês em uma praia específica do município.

Quanto à fiscalização das obras, segundo o representante da gestão da Secretaria Municipal do Meio Ambiente, os projetos passam pela Secretaria de Tributos, de Infraestrutura e depois pela Secretaria de Meio ambiente, assim, acredita-se que a fiscalização das três secretarias previne as construções nas Orlas. No entanto, na pesquisa de campo foram identificadas obras irregulares, a exemplo de várias casas construídas em terras da União no Pontal de Coruripe, a construção do muro de contenção marinha para proteger as casas à beira mar e em áreas de mangues, e a presença de barracas na orla do povoado Lagoa do Pau.

\section{CONSIDERAÇÕES FINAIS}

O uso e apropriação da natureza na borda marítima do Pontal de Coruripe e da Lagoa do Pau estão associados basicamente às práticas recreativas e ao veraneio, entremeados em forma de "mosaico" com práticas tradicionais das comunidades, a exemplo da pesca, e com as residências e pequenos negócios dos moradores locais.

A vilegiatura marítima tem sido a principal responsável pelas alterações espaciais, acarretando em descaracterização paisagística do povoado Pontal de Coruripe na qual as casas de segunda residência, juntamente com a infraestrutura dos serviços, foram tomando o lugar dos coqueirais e das residências da comunidade local. Atualmente, a parte da orla que possui urbanização consolidada possui pouca faixa de praia, considerando a construção de contenção 
marinha para proteger as casas e as infraestruturas de serviços receptivos situadas na faixa da orla marítima.

Já na Lagoa do Pau, a vilegiatura marítima se expandiu em áreas não urbanizadas, e atualmente há uma crescente valorização imobiliária no espaço receptor, expressa pela presença de vários loteamentos. No entorno do povoado surgiram loteamentos que resultaram na construção de condomínios residenciais bem próximos à praia ou em frente a ela, em áreas frágeis em termos ecológicos.

Em termos de infraestrutura, foram poucas as iniciativas do governo local, e é evidente a ausência de profissionais qualificados nos órgãos competentes. No que se refere à infraestrutura, os aspectos positivos se associam à pavimentação das vias, que facilita o acesso da população e dos turistas ou visitantes. No entanto, o transporte urbano é ainda ineficiente e acaba dificultando o fluxo para outras praias. As estruturas espaciais das orlas são desordenadas e não foram executados diagnósticos para implementação de equipamentos no Pontal e na construção dos quiosques na Lagoa do Pau. A participação comunitária, um princípio central da gestão descentralizada proposta pelos instrumentos de ordenamento territorial e turístico no Brasil, ainda precisa de maior atuação na orla marítima de Coruripe.

Tanto no Pontal quanto na Lagoa do Pau há ausência de fiscalização e de controle das práticas turísticas por parte dos órgãos competentes. Os órgãos municipais têm desenvolvido poucas ações que possibilitem o desenvolvimento do turismo e o ordenamento territorial da orla. Ademais, possuem equipes técnicas sem formação específica e um quantitativo que não supre as necessidades de ordenamento. Na verdade, são poucas as iniciativas levadas a cabo pelo poder público municipal.

\section{REFERÊNCIAS BIBLIOGRÁFICAS}

ABRAHÃO, Cinthia Sena; TOMAZZONI, Edegar Luis. Turismo de segundas residências no Litoral Sul do Brasil: uma discussão sobre seu dimensionamento e relevância para a atividade turística contemporânea. Revista Brasileira de Turismo. São Paulo, 12(1). p. 80-101, jan./abr. 2018

ALAGOAS. Decreto No 4.098, de 14 de janeiro de 2009. Acesso: 22/05/2018. Disponível: http://www.semarh.al.gov.br/meio-ambiente/projeto-orla/Decreto_4098.pdf

Plano de Desenvolvimento Integrado do Turismo Sustentável PDTIS: Polo Lagoas e Mares do Sul. Alagoas. Ago. 2011. Disponível em: <http://www.turismo.gov.br/sites/default/turismo/DPROD/PDITS/ALAGOAS/PDITS_LAG OA_E_MARES_DO_SUL.pdf > Acesso em: 20 de maio de 2017. 
Plano Estratégico de Desenvolvimento do Turismo 2013-2023. Maceió. 2013.

Relatório das Atividades de Gestão Costeira 2010/2014. Superintendência de Meio Ambiente: Maceió, 2014.

BANCO DO NORDESTE DO BRASIL S.A. Relatório final do projeto BR 0204. Programa de Desenvolvimento do Turismo no Nordeste. PRODETUR/NE I. 2005. Disponível em: <http://edi.bnb.gov.br/content/aplicacao/prodetur/downloads/docspdf > Acesso em: $27 \mathrm{de}$ janeiro de 2018.

BRASIL. Decreto No 5.300, de 7 de dezembro de 2004. Acesso: 22/01/2018. Disponível em: <http://www.planalto.gov.br/ccivil_03/_ato2004-2006/2004/decreto/d5300.htm> Acesso em: 27 de janeiro de 2018.

. Ministério do Turismo. Turismo de sol e praia: orientações básicas. $2^{\mathrm{a}}$ ed. Brasília, DF: Ministério do Turismo, 2010.

Política e Plano Nacional do Turismo: Gestão Descentralizada Territórios e Instituições. 2013. Disponível em: <http://www.turismo.gov.br> Acesso: 27/08/2018.

CORIOLANO, Luzia Neide Menezes Teixeira. Turismo e meio ambiente: interfaces e perspectivas. In: CORIOLANO, Luzia Neide Menezes Teixeira; VASCONCELOS, Fábio Perdigão. $O$ turismo e a relação sociedade e natureza: realidades conflitos e resistências. Fortaleza: EdUECE, 2007. p. 19-43.

CRUZ, Rita de Cássia Ariza da. Introdução à geografia do turismo. São Paulo: Roca, 2003.

Políticas públicas de turismo no Brasil: território usado, território negligenciado. Revista Geosul, Florianópolis, v. 20, n. 40, 2005.

DANTAS, Eustógio Wanderley Correia; ALVES, Larissa da Silva Ferreira. Nordeste turístico e políticas de ordenamento do território. Fortaleza: Imprensa Universitária, 2016.

DIAS, Reinaldo; AGUIAR, Marina Rodrigues de. Fundamentos do turismo: conceitos formas e definições. Campinas, SP: Editora Elínea, 2002.

DINIZ, Marco Túlio Mendonça; VASCONCELOS, Fábio Perdigão. Turismo, territórios e conflitos de uso do solo no Distrito de Jacaúna, Aquiraz-CE. In: Luzia Neide Coriolano; Fábio Perdigão Vasconcelos. (Org.). Turismo, território e conflitos imobiliários. Fortaleza: EdUECE, 2012, p. 1-432.

DIÉGUES JÚNIOR, Manuel. (1912-1991) O banguê nas Alagoas: traços da influência do sistema econômico do engenho de açúcar na vida e na cultura regional. $3^{\text {a }}$ ed. Maceió: EDUFAL, 2006. (Coleção Nordestina).

FONSECA, Vania; VILAR, José Wellington Carvalho; SANTOS, Max Alberto Nascimento. Reestruturação territorial do Litoral de Sergipe. In: VILAR, José Wellington Carvalho; ARAÚJO, Hélio Mário de. (Orgs.). Território, meio ambiente e turismo no Litoral sergipano. São Cristóvão/SE: Editora da UFS, p. 40-60, 2010.

GÓMEZ OREA, Domingo; GÓMEZ, Alejandro Villarino. Ordenamiento territorial: Una aproximación conceptual y su aplicación al Cantón Cuenca - Ecuador. Revista de La 
Universidad del Azuay. Equador, n. 57. 2012 p. 29-88. Disponível em: $<$ https://www.uazuay.edu.ec/bibliotecas/publicaciones/UV-57.pdf> Acesso em 20/10/2017.

IBGE. Censo Demográfico. Rio de Janeiro, 2010.

IBGE. Produto Interno Bruto dos Municípios 2010-2014. Rio de Janeiro: IBGE, 2016. Disponível em: <http://www.ibge.gov.br/home/estatistica/economia/pibmunicipios/2014/default_base.shtm>. Acesso: 18/10/2018.

LEMOS, João Ribeiro de. Coruripe: sua história, sua gente, suas instituições. Maceió: Ed. Do Autor, 1999.

MADRUGA, Antonio Moacyr. Litoralização: Da fantasia de liberdade à modernidade autofágica. Dissertação (Mestrado em Geografia), Universidade de São Paulo, São Paulo, 1992.

MELO, Josandra Araújo Barreto de. Ordenamento territorial e sustentabilidade: um diálogo possível?. Caminhos de Geografia. Uberlândia, v. 11, n. 33. p. 220 - 229, 2010.

MINISTÉRIO DO MEIO AMBIENTE (MMA). Projeto Orla: fundamentos para gestão integrada. Ministério do Meio Ambiente, Ministério do Planejamento, Orçamento e Gestão (MMA). Brasília: 2006. Disponível em: <http://www.mma.gov.br>Acesso: 20 de junho de 2017.

MORAES, Antônio Carlos Robert. Contribuições para a gestão da zona costeira do Brasil: Elementos para uma geografia do litoral brasileiro. São Paulo: Annablume, 2007.

MORAES, Antônio Carlos Robert; ZAMBONI, Ademilson. Construindo o conceito de orla marítima. In: MINISTÉRIO DO MEIO AMBIENTE. Subsídios para um projeto de gestão. Brasília: MMA e MPO, 2004. (Projeto Orla).

PAIVA, Marina Mujica de. Resposta local ao turismo: resiliência cultural e desenvolvimento local no povoado do Pontal de Coruripe. Dissertação (Mestrado em Desenvolvimento e Meio Ambiente: Desenvolvimento Sustentável). Maceió: UFAL, 2010.

PNGC II. Plano Nacional de Gerenciamento Costeiro II. Disponível em: <http://www.mma.gov.br/estruturas/orla/_arquivos/pngc2.pdf> Acesso: 22/01/2018.

SANTOS, Milton. A Natureza do Espaço: Técnica e Tempo. Razão e Emoção. $4^{a}$ ed. São Paulo: Editora da Universidade de São Paulo, 2006.

TURATO, Egberto Ribeiro. Decidindo quais indivíduos estudar. In: TURATO, Egberto Ribeiro. Tratado da metodologia da pesquisa clínico qualitativa. Construção teóricoepistemológica, discussão comparada e aplicação nas áreas da saúde e humanas. 3 ed. Petrópolis, RJ: Vozes; 2008. p. 351-68.

SANTOS, Carla Norma Correia dos. Entre o litoral sul de Sergipe e o litoral norte da Bahia: onde as políticas territoriais se encontram. Tese (Doutorado em Geografia). São Cristóvão: Universidade Federal de Sergipe, 2017. 
SILVA, Priscylla Maria Ferreira da. Ciclo de vida da área turística: o caso do Pontal de Coruripe-AL. Dissertação (Mestrado em Arquitetura e Urbanismo: Dinâmicas do Espaço Habitado). Maceió: Universidade Federal de Alagoas, 2016.

Recebido em Julho de 2018

Aprovado em Dezembro de 2018

Publicado em Fevereiro de 2019 